\title{
A Simulation Model of Pretrial Felony Case Processing: A Queuing System Analysis
}

\author{
William McAllister, ${ }^{1}$ James Atchinson, ${ }^{2}$ and Nancy Jacobs ${ }^{3}$
}

\begin{abstract}
Case processing tends to be examined with data analysis or evaluation designs. Both limit our understanding of how case processing as a whole operates and how its parts relate to each other. This article suggests queue simulation modeling as a method for dealing with these issues. We report here the initial development and analysis of a queuing model of arraignment to trial assignment. Conceptualizing on the basis of court functions and empirical findings, rather than institutional structures, we conceive a five-stage pretrial process. Using case-level, rather than system-level data, we construct a single-server, multiphase queuing model and use the model to simulate the behavior of a pretrial case processing system. Simulations show the strong impact of the final phase (trial assignment) on the entire system and that most of this impact is delay rather than service. The system is then analyzed using a factorial design that systematically alters model parameters thought to be important determinants of performance. Simulations are run for each possibility in the design, and analysis of variance is used to examine results. Analysis confirms prior results concerning final phase impact and points specifically to the import of phase capacity and exit rate. The utility of modeling is considered by suggesting some policy implications of the results for judicial staffing and behavior.
\end{abstract}

KEY WORDS: queuing; simulation; pretrial case processing.

\section{INTRODUCTION}

Research on felony case processing tends to build explanations in the form of regression models, modified experiments, or evaluation impact designs by employing variables having to do with a particular case or court(s) (Flemming et al. 1987; Luskin and Luskin, 1987, 1988; Sipes et al., 1980; Neubauer et al., 1981b; Mahoney et al., 1985; Church, 1982). This work has indicated myriad, diverse, and, at times, conflicting sets of variables

${ }^{1}$ Criminal Justice Research Center, John Jay College, CUNY, 899 Tenth Avenue, New York, New York 10019.

${ }^{2}$ State of Vermont, Agency for Human Services, Waterbury, Vermont 05676.

${ }^{3}$ Criminal Justice Research Center, John Jay College, CUNY, 899 Tenth Avenue, New York, New York 10019. 
as important determinants of this process: judicial behaviour (e.g., continuance policy), a court's institutional arrangement, case events (e.g., hearings or motions), crash programs, and cultural forces.

As one group of these researchers points out, however, their findings may be incomplete because the methodologies on which they are based do not allow analyses of how case processing results from the way the system as a whole operates, especially the effect cases have on each other (Flemming et al., 1987). Simulation modeling, queue modeling in particular, is a way of dealing with this concern. In an early appraisal of this method's value, Jennings focused on its core utility: mathematical simulation techniques allow us to construct models "which relate the flow of cases to the actual court operations which give rise to such flow" (Jennings, 1971a, p. 8).

Our primary purpose in this paper is to apply queue theory to case processing to examine the fruitfulness of these techniques in understanding the relationships Jennings and Flemming et al. discuss. We do this by developing and analyzing an initial simulation model of how felony courts process cases to the point where they are resolved through plea bargaining or dismissal or are assigned a trial date.

Unlike most modelers, we are not interested in modeling the flow of cases through the specific institutional features of a particular court system (e.g., Navarro and Taylor, 1967; Jennings, 1971b; Hann, 1973; Reed, 1973; Chaiken et al., 1976, pp. 104-106). We construct a model based on the "major events" described by empirical research and our data analysis as structuring the period from arraignment to trial assignment (e.g., Sipes et al., 1980, pp.6-7). A queue model allows us to formalize this conception of "major events," permitting us to see the systemic relationships among the stages. This focus means an absence of institutional complexity in our model but a gain in ability to generalize.

Similar to the CANCOURT model of the Canadian Criminal Justice System, we build the model on the basis of the "court career" of individual cases (Hann, 1973, pp. 46-49). We do this because the dynamics of a court system are played out at the level of individual actors in the courtroom and because research has emphasized the important role of courtroom-specific networks, norms, and role expectations in affecting case processing (Neubauer, 1974; Eisenstein and Jacob, 1977; Church, 1982; Flemming et al., 1987; Jacobs et al., 1986).

Further, this perspective emphasizes the import of the behavior and interaction of actors in the courtroom. Case processing results from the activities of the judge, the attorneys and the defendant as reflected in the courtroom behavior of each (Luskin and Luskin, 1986, 1987). By using individual case event data collected at the courtroom level, we are able to include probabilities of relevant actors' behavior in the model. This allows 
us to build a behaviorally complex and realistic model, akin to CANCOURT and different from models reliant on aggregate data, which cannot make use of such estimates (e.g., Navarro and Taylor, 1967; also see Jennings, 1971b).

In addition, by using courtroom-level behavioral data, we can better specify the delay and service time components of case processing. At the heart of queuing theory is the promise of modeling system time as delay and service. As Blumstein points out, however, one problem in applying queue theory to court systems is substantively distinguishing these times (Blumstein, 1981, pp. 157-158). The approach here tries to make a dent in this problem.

And finally, we analyze the system generated by the model, using a factorial design. This has the advantages of specifying further the initial conclusions from model evaluation, giving a better understanding of what system features most affect the whole and showing how policy suggestions can be produced from modeling results.

\section{THE DATA AND THE PRETRIAL PROCESS}

To generate the model, we employed data collected for a study of pretrial felony case processing in New York State Supreme Court in Manhattan and Queens Counties (Jacobs et al., 1986). The authors of this study followed a sample of 104 individual cases of interpersonal, violent crimes (homicide, rape, robbery, or felonious assault) from arraignment to disposition by plea or dismissal or to the setting of a trial date. ${ }^{4}$ This is the "individual case" data set.

Observers gathered detailed information at every court appearance of each case, including defense and prosecuting attorney behavior, the judge's response to events at each appearance, the judge's scheduling behavior, the outcome of each appearance, information on and reasons for why a court appearance failed to move a case forward, and other data. [For a more specific description of the data collection, see Jacobs et al. (1986, pp. 231238).] Usually, the court appearance was the analytic unit in the data analysis performed to build the model. The total sample size of this "appearance case" data set was the number of individual sample cases $\times$ mean number of appearances, or $946=104 \times 9.1$. [For a similar data analytic approach, see Hann (1973, pp. 84-86).]

\footnotetext{
${ }^{4}$ At the time data were collected, the New York court system operated under a Master Calendar and was divided into court complexes in each county. These complexes consisted of a calendar part, for pretrial motions and other activities, and five or six trial parts, to conduct hearings as well as trials, for each calendar part. For a more complete institutional description, see Jacobs et al. (1986).
} 
Typically, queuing models employ aggregate system data. We used a case-level sample because aggregate data are not collected on the system features we wanted to model, i.e., the stages between arraignment and pretrial disposition. Furthermore, aggregate system data would not provide estimates of the parameters needed for a courtroom level model. Finally, these data, unlike aggregate system data, enable us to incorporate actor behavior in the model. In particular, they allow us to measure judicial flexibility and responsiveness to actual circumstances and to attorney availability. These are critical in identifying delay and service times.

Statistical analyses of the individual case data indicated the paths cases followed through the pretrial process. Appearance case data were used to generate probability estimates of events and choices which affected case processing. These analyses were used to generate a description of case processing.

As in most courts, pretrial felony case processing in New York City tends to have certain stages or "major events" (Sipes et al., 1y80, pp. 6-7). The existence of common stages is due to courts having to accomplish similar tasks in processing cases, e.g., the formal charge of criminal offenses, the disclosure of information held by the defense and prosecuting attorneys, the assurance of defendant rights, and so forth.

We can conceptualize these tasks being accomplished in distinct court appearances the judge schedules for formal legal presentations by the defense or prosecuting attorney or for judicial decisions. ${ }^{5}$ Taking a simplified view of how a court executes each task, we can theorize that pretrial courtroom work can be accomplished in five appearances: arraignment on initial indictment, filing defense motions, filing prosecution responses to these motions, judge's decision on these motions, and setting a trial date. ${ }^{6}$

\section{GENERAL FORM AND ASSUMPTIONS OF THE MODEL}

The basic model is a series of stages corresponding to these five appearances. Each case must pass through one or more of these before being assigned a trial date, being dismissed, or pleding.

\footnotetext{
${ }^{5}$ In New York City, appearance scheduling is decided by the judge. In some jurisdictions, appearance scheduling is decided by the district attorney or by court administrators. The critical feature for our purpose is that one position does the scheduling. Whatever position that may be is not important here.

${ }^{6}$ Of course, the actual process is less straightforward. Additional appearances are often required for attorneys to file supplementary motions or for particular legal hearings to occur. A judge may schedule further appearances because he or she senses the defendant may be ready to plead, because a trial part is not available, or because attorneys fail to appear. Also, motion filings and the judges' rulings on them do not occur as formally as this abstraction conveys. And some of these activities may be going on simultaneously. The process can be complex and messy.
} 
Figure 1 charts the stages (appearance phases) and their relationships. Each essentially consists of three parts: first, a queue of cases waiting to enter the phase; second, a set of conditions a case must meet to enter; and third, possible outcomes. In general, a case completes one appearance phase and moves to the next, continuing through each until reaching the last phase and leaving the system, i.e., scheduled for trial.

The model describes a single-server queuing system, where the server

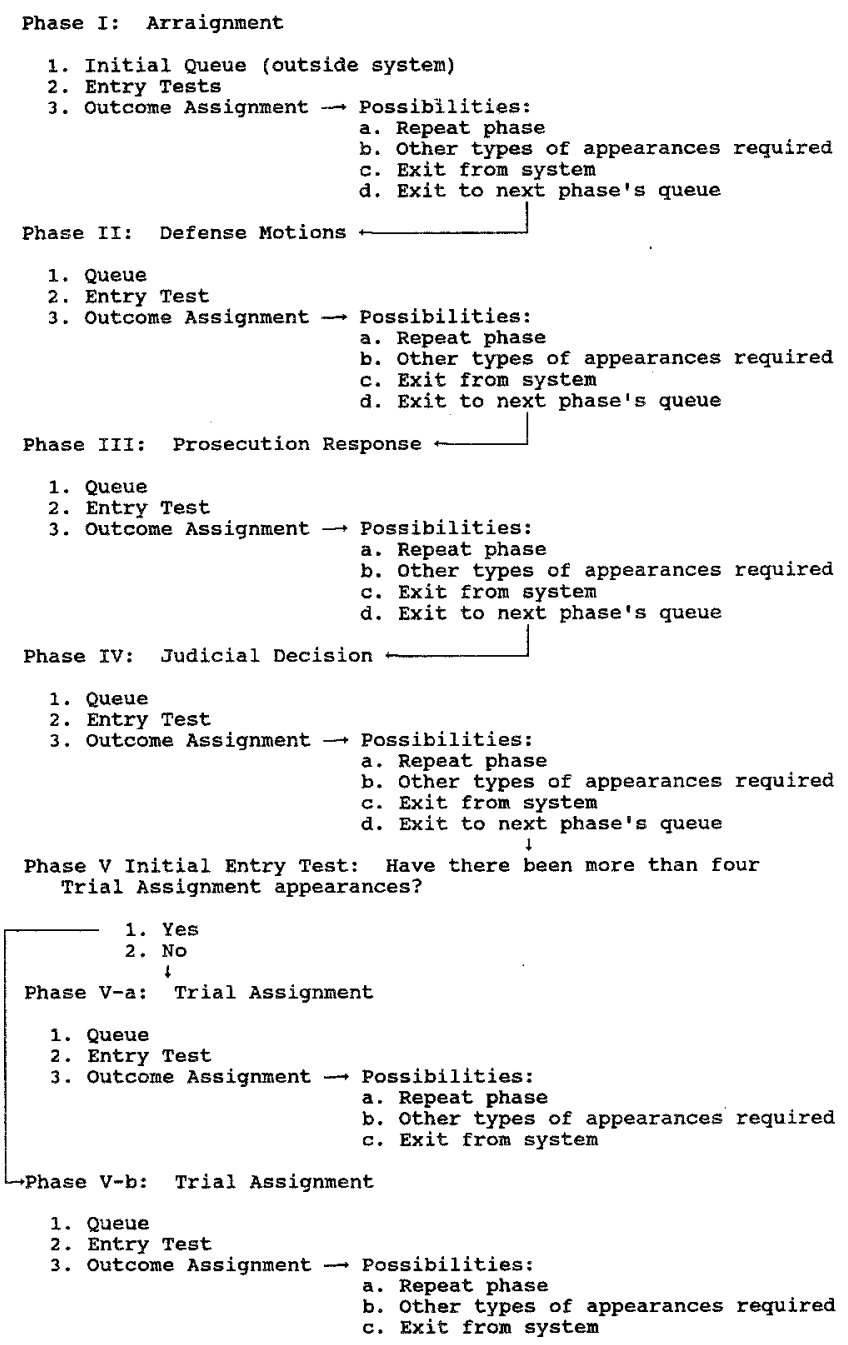

Fig. 1. General flow chart of pretrial felony case processing simulation model. 
is the judge. ${ }^{7}$ This is appropriate for several reasons. Typically in the New York courts, a single judge makes judgments during pretrial processing. Also, the judge is the sole actor formally charged with the responsibility for setting appearance dates. Recognition of the value of a "firm continuance" policy in reducing delay indicates the import of this responsibility (Sipes et al., 1980; Luskin and Luskin, 1987, p. 230). In addition, the judge tends to be the actor who sets the tone for attorney behavior. For instance, he or she is seen to be particularly important in helping shape the norms and attitudes of the local legal culture (Sipes et al., 1980, pp. 25-26). Finally, when things go awry and the problem can be identified, the judge tends to be the one who can get others to respond (Resnick, 1982). This is because the judge has formal power to cause such a response and because he or she tends to have the greatest interest in resolving problems and moving the case along (Flemming et al., 1987, pp. 186-187). ${ }^{8}$

Time advances as the model's clock is updated to the next appearance day in court ("next-event" simulation). For any one case, this day is identified by the interval of days since the previous court appearance. Depending on appearance outcome, this interval is determined by either the distribution of days to the next appearance or equations, both using estimates from the appearance case data.

Finally, the model assumes that the arrival rate is Poisson distributed and cases cycle constantly until the first phase has room. ${ }^{9}$ These are cases in the "Initial Queue" and are considered outside the system until entering the first phase (arraignment). The model calculates no time advancement for cases initially waiting to enter the system. ${ }^{10}$

\footnotetext{
${ }^{7}$ The model is essentially a multiphase system with a single-server in each phase and was written in GPSS. (See Watson, 1981.)

${ }^{8}$ Formally modeling the system as single-server does not mean that case servicing activity by actors other than the judge is not represented in the model. As we shall see, the distributions and equations used to calculate time reflect the behavior of prosecuting and defense attorneys, the corrections system, and other relevant actors.

${ }^{9}$ The model sets a maximum number of cases $(10)$ that can be in a phase at any one time, i.e., phase capacity. Having room in a phase means that, at a particular moment, that maximum has not been reached.

${ }^{10}$ In this regard, the first phase (arraignment) does not exactly replicate the actual situation in the New York courts. Because there were no data to estimate the rate at which cases were actually assigned to judges, we have made the assumptions elaborated above for the initial queue, some of which do not precisely reflect felony arraignment in New York. In addition, because of legal requirements, there is no such thing as "no room" for initial arraignment; the judge will simply increase his or her caseload to hear those due to be arraigned. Thus, cases do not cycle. One result in actuality is a buildup of cases after arraignment-in our model, the formation of a large queue for the defense motions phase. This queue does indeed form when we run the simulations.
} 


\section{APPEARANCE-PHASE LOGIC}

Processing is similar for each phase, consisting of a method to control entry into the phase and one to determine the result of an appearance in that phase. See Fig. 2.

A case residing in a phase queue is subjected to "phase entry tests," which evaluate whether there is capacity in the phase (in effect, room on the judge's court schedule) and whether the attorneys and defendant are all available. Attorney and defendant availability is based on percentages from the appearance case data, which were selected by independently generated random numbers. We calculated separate attorney and defendant availability percentages for each state. Capacity is estimated by the daily average number of cases heard by judges handling the sample cases. At the time of data collection, the mean was about 50 . Apportioned equally among

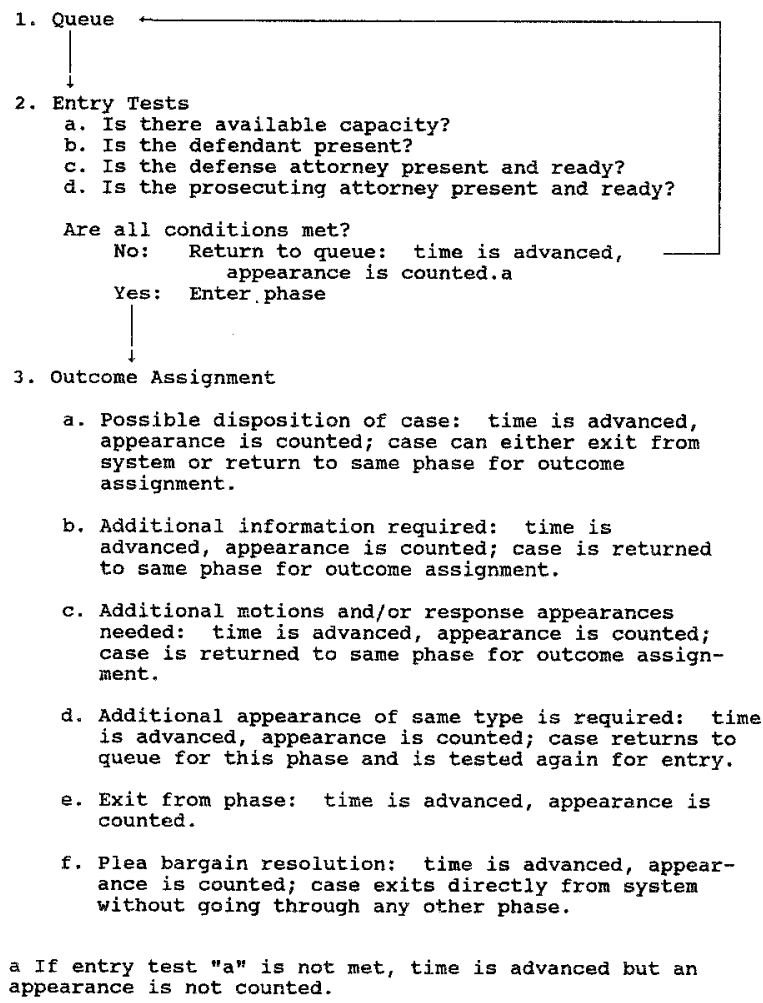

Fig. 2. General logical structure of each phase. 
the five phases, this yields a capacity of 10 per phase. ${ }^{11}$ Table I presents the participant availability and capacity statistics used in running the simulations.

The probability of a case entering a phase is the joint probability of the three participants' availability (see Table I) and whether or not the judge has room on his or her court schedule. All four conditions must be met for phase entrance, or the case is rescheduled and kept in queue. An appearance is counted and time advanced only if rescheduling results from attorney or defendant unavailability. If lack of room is the cause, time is advanced but an appearance is not counted.

Table I. Base-Level Parameters of the Five Appearance Phases for the Simulation Model

\begin{tabular}{|c|c|c|c|c|c|}
\hline \multirow[b]{2}{*}{ Phase } & \multirow[b]{2}{*}{ Capacity } & \multicolumn{3}{|c|}{ Participant availability $^{a}$} & \multirow[b]{2}{*}{$\begin{array}{l}\text { Phase exit } \\
\text { prob. }^{b}\end{array}$} \\
\hline & & Defendant & $\begin{array}{l}\text { Defense } \\
\text { attorney }\end{array}$ & $\begin{array}{c}\text { Prosecuting } \\
\text { attorney }\end{array}$ & \\
\hline Arraignment & 10 & 0.964 & 0.898 & 0.942 & 0.643 \\
\hline Defense motions & 10 & 0.999 & 0.746 & 0.921 & 0.707 \\
\hline Prosecution response & 10 & 0.984 & 0.820 & 0.738 & 0.683 \\
\hline Judicial decision & 10 & 0.952 & 0.726 & 0.887 & 0.447 \\
\hline Trial assignment & 10 & 0.968 & 0.668 & 0.545 & 0.289 \\
\hline Trial assignment $^{c}$ & & 0.937 & 0.611 & 0.603 & 0.222 \\
\hline
\end{tabular}

${ }^{a}$ Participant availability probabilities are independent of each other.

${ }^{b}$ Phase exit probability is the chance of leaving a phase (possibility "c" in Fig. 1 or "e" in Fig. 2) once entry test conditions have been met.

${ }^{c}$ As we described in the text, two sets of criteria govern entrance into the trial phase, one set for cases with four or fewer trial assignment appearances and a second set when the number of those appearances was greater than four.

${ }^{11}$ The requirement of phase room availability imposes a limit on the number of appearances a judge can handle at any time. Since judges can hear just so many cases over a specified time period, this is no different from the way actual court systems work. [The CANCOURT model also specifies phase capacity, though it estimates this number in a different fashion (Hann, 1973, pp. 46-69, 75-76).] Our model has the same capacity limits for each appearance phase. We did this for two reasons. In the absence of any phase estimates and with a cue from Occam's razor, we decided that a simple assumption is better than a complex one. Also, this allows us to understand better how the system behaves by holding constant phase and, thus, system capacity as other aspects of the system vary. In reality, a judge exercises more flexibility in the mix of appearance types he or she schedules, though overall capacity may remain constant, and such flexibility may be an important tool in a judge's moving cases along. Thus, the import of judges and the speed with which cases move may be underestimated in our model. See Blumstein (1981) for a discussion of the problem of assuming a fixed service rate in queuing models of courts. 
There are six possible "outcome assignments." The first three (Fig. 2, 3a to 3c) allow for case disposition or for rescheduling in the current phase. The next two alternatives ( $3 \mathrm{~d}$ and $3 \mathrm{e}$ ) schedule the case to reenter the same phase or to enter a subsequent phase. In the final possibility (3f), the case is resolved through a negotiated plea: it goes directly to final phase and exits the system.

For every possibility, the model counts an appearance and advances time. To advance time in each of the first three options, we calculated a distribution of days to next appearance from the appearance case data and used a random number generator to select values from these distributions for use in the simulation.

For options $3 \mathrm{~d}$ and $3 \mathrm{e}$, data analysis indicated that judicial scheduling behavior was associated with appearance productivity and with prosecution or defense time requests. As a result, OLS regression was used to determine time advancement. Equations were developed from the appearance data for initially scheduling an appearance in the next phase and for rescheduling an appearance within the same phase (if the initially scheduled appearance failed to accomplish the task of that phase). The most critical variables in the equations were a dummy for productivity and attorney time requested (prosecution, defense, both, neither). Values for these variables were picked by a random assignment process that selected from the distribution of each variable in the appearance case data. (See Appendix for the equations and for a more specific description of clock advancement.)

Because they determine $90 \%$ of clock advancements, these equations are critical. Relying on them captures some of the behavioral complexity and realism involved in the pretrial process. In particular, through these equations the model reflects the nonjudicial as well as the judicial conduct that determines the time to next appearance, thereby incorporating service effort of nonjudicial actors.

The queue, entry tests, and outcome assignments operate in the same fashion for each of the first four phases. Final phase modeling is similar but has several additional elements.

\section{LOGIC OF THE EXIT PHASE}

The last phase is crucial in this model because most cases must pass through this stage to exit the system. Thus, the case-processing rate for the trial assignment phase is essentially the rate for the system as a whole.

This is not to gainsay the argument of various studies that case management at all stages can reduce court delay. By developing a model which emphasizes the importance of the final phase to the entire process, we have simply acknowledged what tends to be the actual situation in most court 
systems. Legal requirements exist that facilitate case movement through the early phases, and defense and prosecuting attorneys as well as judges tend to have a stronger interest in moving cases through initial stages than they do in having a case leave the system once it nears a final stage. Note, in Table I, the exit probability for the trial assignment phase is much less than for the other phases. Finally, the backlog of pending cases at the end of the pretrial process that most court systems have and the ability of "crash" programs to improve court performance by eliminating these backlogs suggest, taken together, the importance of final phase processing for the operation of the system as a whole.

The model considers a case as having completed pretrial processing when it is assigned to trial. The logical structure of this trial assignment phase is essentially the same as for prior stages. Two modifications are made to simulate better the actual system's behavior.

First, if a case has gone through four appearances without a trial date being set, it moves to a second part of the phase. This is because the appearance case data show that a large number of appearances is common in this phase. (See Fig. 1, $\mathrm{Va}$ and $\mathrm{Vb}$.) Multiple appearances are necessary because trial parts are not free, because witnesses or evidence for trial is unavailable, because defendants fail to come or be brought to court, or most commonly, because attorneys are unavailable (as a part of their tactical maneuvering). ${ }^{12}$

As Table I indicates, attorney availability and outcome assignment percentages differed for cases with more than four appearances in this phase. To reflect this, the second part to the exit phase was constructed by using attorney availability and outcome assignment percentages different from those in the first part. After four appearances in this phase without exiting, a case is subjected to the second set of entry test probabilities and to different scheduling functions. ${ }^{13}$

Second, and more important, this phase differs from the others because the judge's involvement with a case ends with this stage. Under the singlejudge, courtroom perspective assumption, the main alternatives can only be additional appearances to set a trial date or resolution of the pretrial processing of the case, i.e., a plea is entered or a trial date assigned. Thus, the outcome assignment function differs from prior phases by recognizing only the scheduling of another appearance in the trial assignment phase. Scheduling to the next phase (3e) is replaced by the system exit option.

\footnotetext{
${ }^{12}$ In the individual case data, this phase required 1 to 23 appearances to be completed. This is similar to what Jennings found (Jennings, 1971b, p. 15).

${ }^{13}$ Splitting this phase into two parts allows the model to replicate better the performance of the actual system. We are not suggesting that the final phase actually has this structure.
} 


\section{EVALUATION}

The model was evaluated by executing three simulation runs, using a different random number series to simulate case arrival. Each was run until 500 cases passed through the system and exited. ${ }^{14}$ Table $I I$ shows the processing pattern of the model. Statistics are averages of the three simulations, based on the 500 cases that exited per simulation. Since this model reschedules cases, sending them through the same processes multiple times rather than simply holding them in queue, case counts are greater for each phase than they would be in the actual system. The shape of the distributions for the appearance count and time distribution is similar to that for the individual case data, i.e., fairly normal distributions with a skew to the right indicating a small proportion of cases with many appearances and long times. (See Appendix for model validation.)

Table II is useful for identifying where backups form. The most important result is that the largest queue develops at the final phase. This queue is six times the size of the next largest queue, with utilization of the phase nearly $100 \%$. Clearly, this is the major backlog in the model.

A large final-phase queue is predictable from queuing theory. The relationship among the rate at which cases arrive at a system, $A$, the rate at which a system services cases, $S$, and the size of the expected queue is Queue $=A^{2} /(S *(S-A)) .{ }^{15}$ An implication is that queues will increase quickly whenever the rates at which cases arrive at and are processed by the system are close to the same levels. The last column in Table I indicates

Table II. Queue and Phase Pattern of the Simulation Model

\begin{tabular}{lrrrrr}
\hline & \multicolumn{2}{c}{ Number of cases } & & \multicolumn{2}{c}{ Number of days } \\
\cline { 2 - 3 } \cline { 5 - 6 } Appearance phase & Queue & Phase & & Queue & Phase \\
\hline Arraignment & 65.32 & 9.76 & 134.21 & 21.75 \\
Defense motions & 67.83 & 9.77 & & 160.79 & 25.29 \\
Prosecution response & 6.04 & 8.13 & & 16.78 & 22.40 \\
Judicial decision $^{a}$ & 1.52 & 7.02 & & 4.22 & 19.36 \\
Trial assignment $^{a}$ & 376.47 & 9.97 & 537.52 & 21.52 \\
\hline
\end{tabular}

${ }^{a}$ The results for the two parts of this phase were combined, since the number of cases in the first part almost entirely accounts for the result. For example, the mean queue size for the first part is 356 cases.

\footnotetext{
${ }^{14}$ For initialization of the simulation model to achieve a steady state, 375 cases were used.

${ }^{15}$ This assumes the system is in steady state and has a single-server, arrival rate is Poisson distributed, queue discipline is first come/first served, and there is no balking (Watson, 1981, pp. 151-152).
} 
that the final-phase processing rate is much lower than for previous phases and closer to the rate at which cases arrive at the final phase. Hence, the queue tends to build quickly.

Since, in general, all necessary work in a case has been done prior to the last phase, it might seem surprising to find such a bottleneck. Yet this is exactly what occurs in the New York City courts and what tends to occur in most pretrial processing (Church et al., 1978, pp.68-69). In addition, there is a buildup getting into the second phase, once arraignment has been completed. This also reflects the behavior of the actual system. ${ }^{16}$

Final-phase processing affects the operation of the entire system in a more subtle way. This rate has a significant influence on total system time because whenever a case does not meet the multiple entry conditions for any phase, it is exposed to the probabilities of rescheduling by being sent anew through the queue. ${ }^{17} \mathrm{~A}$ decreased processing rate for the final phase not only will affect queue size for that phase but will lengthen the mean case processing time for the entire system by increasing the rescheduling times for any phase operating at or near maximum capacity. ${ }^{18}$

Table II also indicates the relationship between delay and service times. Total system processing time is the sum of delay time and service time or, in queuing models, transition time in queue and in phase (Blumstein, 1981, pp. 157-158). The utility of a queuing model in distinctly modeling these two times is undermined to the extent that delay and service times cannot be estimated exclusive of one another. Because time in queue is based on rescheduling equations which use only rescheduled cases, i.e., for the most part, cases not heard because of delay problems, we were able to minimize the degree to which servicing would have occurred during time in queue.

Also, estimates of time in phase will tend to exclude delay time because phase time is based on scheduling equations that are distinct from rescheduling equations and assumed to represent the judge's best estimate of the time required for service by all actors. The warrant for this assumption is that, for professional and organizational reasons, judges are interested in

\footnotetext{
${ }^{16}$ For reasons cited in footnote 10 , the size of the initial queue is most likely an artifact of the model and does not reflect the real court system's dynamic. Thus, it is not as analytically useful as queues for other phases, which are modeled using the appearance case data.

${ }^{17}$ The model counts an appearance when a case is denied entrance to a phase because one or more participants is not available. No appearance is counted (but time is advanced) for a case not meeting the requirement of available phase capacity.

${ }^{18}$ This dependency between the final-phase queue and prior queues occurs because we ran each simulation until 500 cases exited from the system. As the final-phase queue lengthens, the system requires more "time" to achieve the goal of exiting 500 cases. This causes more cases to enter into and remain in the system. Queues build for phases approaching $100 \%$ utilization because these phases have no capacity to handle the greater number of cases in the system as a result of the system's slowing down.
} 
moving cases as quickly as possible (Resnick, 1982; Flemming et al., 1987). To the extent that this assumption is incorrect, time in phase will not be service time exclusive of delay.

Table II indicates that processing time is comprised predominantly of delay time. Using a weighted-average measure of transition times, where the weights are the number of cases entering a phase, we estimate that delay (queue) time is almost 14 times service (phase) time. In addition, the largest single contributor to the weighted-average measure for delay is the finalphase queue, as it has at least 1.5 more cases and a 3.4 longer transition time than any other phase. Thus, the model suggests that final-phase processing is the key to system delay.

\section{SYSTEM ANALYSIS}

The model can be used to analyze the effect on system performance of altering levels of three independent variables thought to be important determinants of case processing in the trial assignment stage. These are phase capacity, phase entry rate, and case processing rate.

Final-phase capacity is simply the maximum number of cases the model permits that phase to handle. The proposition is straightforward: augmenting the capacity of this phase reduces its queue, thereby enhancing system performance. Since this model assumes a single-judge perspective, we cannot increase the number of judges to expand court capacity. Instead, we vary the number of final-phase cases a single judge can hear.

The second variable expected to affect case processing is the rate at which cases enter the final phase. Increasing this rate should diminish the queue, boosting processing speed as a result. Data analysis demonstrated that the probability of attorneys being ready for the final phase was much lower than for previous phases (see Table I). Thus, to test for this effect, we vary the rate of attorney availability for the final phase.

The last independent variable is the final-phase exit probability, i.e., the expectation that a case which has entered this phase will be resolved at any given appearance. To test this factor's effect, we vary the rate at which cases leave the phase, i.e., the case closure rate.

Four aspects of the system are used to indicate how well it processes cases. Two are the mean number of appearances and of days required for the 500 cases in each simulation to pass through the system. These are obvious indicators of court processing performance, and one or both have been used in studies of court delay (e.g., Mahoney et al., 1985, p. 10).

The third measure is mean size of the defense motions queue. Since this variable indicates, in effect, the number of cases at the beginning of 
the system waiting to be processed, as the system speed changes this queue's size should vary concomitantly.

The last system performance measure is mean queue size for the trial assignment phase. Since this queue is the point at which the system most seriously backs up, affecting this feature of the process should cause system performance to improve or deteriorate.

The analytic goal is to understand the relative impact that final-phase capacity, entry rate, and exit rate have on these system performance indicators. We do this by employing a simple factorial design for dichotomous variables, i.e., fixing a value above and below the base simulation values for each independent variable and running simulations for all eight possible combinations of these values. ${ }^{19} \mathrm{We}$ then evaluate the impact of these levels on system performance indicators.

We varied the independent variables by $20 \%$. For example, since phase capacity for the base runs was 10 , simulations were run with capacity increased to 12 cases and reduced to 8 . We use these levels because they provided sufficient variation to meet our purpose of seeing how the system responds to changed conditions. We do not presume that they represent realistic ranges for any variable. For each possibility in the factorial design, three simulations of 500 cases each were run $\left(2^{3} \times 3=24\right.$ simulations $)$.

\section{FINDINGS}

In Table III, the simulation results are expressed as positive or negative percentages relative to averages of the three base simulations. The last row contains data from the base runs; these are actual counts and not percentages.

The first three columns indicate high and low levels for each independent variable. The next four columns reflect impact on the dependent variables measuring system performance. For example, when all three independent variables are set low, i.e., the capacity is 8 cases per phase and the phase entry and case closure rates are $20 \%$ lower than they were for the base simulations, the mean size of the defense motions queue increases by $32.8 \%$, the mean number of days to process cases increases by $34.6 \%$, the mean number of appearances increases by $10.4 \%$, and the mean size of the final phase queue increases by $104.6 \%$.

The major findings are that (a) improving the entry rate alone has no impact (row 2), (b) expanding the capacity alone has a noticeable result

\footnotetext{
${ }^{19} \mathrm{We}$ are not attempting to find an optimum combination of these variables but are simply using this design to understand the relative effect of each factor. Technically, this is a between-subjects, orthogonal design.
} 
Table III. Effect of Varying Determinants of System Performance, Expressed as a Percentage of Base Case Simulations

\begin{tabular}{|c|c|c|c|c|c|c|}
\hline Capacity & $\begin{array}{l}\text { Phase } \\
\text { entry } \\
\text { rate }\end{array}$ & $\begin{array}{l}\text { Exit } \\
\text { rate }\end{array}$ & $\begin{array}{l}\text { System } \\
\text { processing } \\
\text { time } \\
(\%)\end{array}$ & $\begin{array}{c}\text { Number } \\
\text { of } \\
\text { appearances } \\
(\%)\end{array}$ & $\begin{array}{c}\text { Defense } \\
\text { motions } \\
\text { queue } \\
(\%)\end{array}$ & $\begin{array}{c}\text { Trial } \\
\text { assignment } \\
\text { queue } \\
(\%)\end{array}$ \\
\hline 1. Low & Low & Low & +34.6 & +10.4 & +32.8 & +104.6 \\
\hline 2. Low & High & Low & +27.5 & +10.4 & +23.9 & +116.9 \\
\hline 3. High & High & Low & +7.6 & +8.8 & +8.4 & +14.3 \\
\hline 4. High & Low & Low & +6.1 & +3.1 & -1.1 & +13.7 \\
\hline 5. Low & Low & High & +3.3 & -1.4 & -5.1 & +13.1 \\
\hline 6. Low & High & High & 0.5 & +1.4 & -12.1 & +11.3 \\
\hline 7. High & High & High & -22.4 & -9.1 & -5.2 & -52.6 \\
\hline 8. High & Low & High & -25.8 & -12.9 & -8.6 & -44.1 \\
\hline \multicolumn{3}{|c|}{ Mean Base Case Simulation ${ }^{a}$} & 806.3 & 28.0 & 67.8 & 356.2 \\
\hline
\end{tabular}

${ }^{a}$ Base case simulation figures are counts and not percentages. For example, the average system processing time for the base case simulations is 806.3 days.

(row 4), (c) increasing only the exit rate has a powerful effect (row 5), and (d) improving the exit rate and capacity jointly has the greatest impact (row 8).

Table III makes clear that the final-phase exit rate is the single most important feature affecting the system. The four worst system performances for each measure occur when the exit rate is low, and the four best performances occur when that rate is high. Further, the impact of increasing the capacity is greatest in combination with an improved exit rate (rows 7 and 8 versus rows 2 and 3). In addition, the system performs better when exit rate alone is set high than when capacity and entry rate are jointly set high (row 5 versus row 3 ). And finally, Table III also shows that the final-phase capacity, by itself, has a strong impact on system performance, but its impact is neither as general nor as great as that of the exit rate.

The data can be examined further. Analysis of variance of the means for the 24 simulations permits a statistical evaluation of main and interaction effects of the three independent variables. We ran models for main effects and for the three possible two-way interactions. Tables IV through VII display the data for main and interaction effects on each of the dependent variables.

These results support the previous findings. The phase entry rate is not related to system performance. Both the capacity and the case closure rate have strong effects on the performance measures, but the $F$ scores are consistently higher for the exit rate and are statistically significant across all system indicators for the exit rate. The interaction term for phase capacity 
Table IV. Analysis of Variance Model for Effects on System Performance Measures: System Processing Time

\begin{tabular}{lccc}
\hline & & $F$ & $\mathrm{df}$ \\
\hline & (a) Main effects & & \\
& & $70.88^{*}$ & 1 \\
Phase capacity & & 0.22 & 1 \\
Phase entry rate & & $103.16^{*}$ & 1 \\
Case closure rate & & $58.09^{*}$ & 3 \\
\multicolumn{1}{c}{ Model } & & & \\
& & & \\
& & & \\
& & & \\
& & $67.55^{*}$ & 1 \\
Phase capacity & & 0.21 & 1 \\
Phase entry rate & & $98.32^{*}$ & 1 \\
Case closure rate & & 0.06 & 1 \\
Phase capacity $\times$ case closure & $41.54^{*}$ & 4 \\
Model & & \\
& $R^{2}=89.7 \%$ & \\
\hline
\end{tabular}

$* P<0.002$

Table V. Analysis of Variance Model for Effects on System Performance Measures: Number of Appearances

$\longrightarrow$ F df

(b) Main effects

Phase capacity

Phase entry rate

Case closure rate

$\begin{array}{cc}12.10^{*} & 1 \\ 1.90 & 1 \\ 39.54^{*} & 1 \\ 17.85^{*} & 3\end{array}$

Model

$$
R^{2}=72.8 \%
$$

(b) Interaction effects

Phase capacity

Phase entry rate

$12.89^{*} \quad 1$

Case closure rate

$2.02 \quad 1$

Phase capacity $\times$ case closure

$42.12 * \quad 1$

Model

$$
R^{2}=75,8
$$

${ }^{*} P<0.002$. 
Table VI. Analysis of Variance Model for Effects on System Performance Measures: Defense Motions Queue

\begin{tabular}{lll}
\hline & $F$ & $\mathrm{df}$ \\
\hline
\end{tabular}

(a) Main effects

$\begin{array}{lcc}\text { Phase capacity } & 2.96 & 1 \\ \text { Phase entry rate } & 0.01 & 1 \\ \text { Case closure rate } & 10.91^{*} & 1 \\ \text { Model } & 4.63^{* * *} & 3 \\ & & \end{array}$

(b) Interaction effects

Phase capacity

Phase entry rate

$\begin{array}{cc}3.46 & 1 \\ 0.01 & 1 \\ 12.78^{*} & 1 \\ 4.43^{* * *} & 1 \\ 5.17^{* *} & 4\end{array}$

Phase capacity $x$ case closure rate

Model

$R^{2}=52.1 \%$

$$
\begin{array}{rl}
* P & <0.002 . \\
* * P & <0.01 \\
* * * & P<0.05
\end{array}
$$

Table VII. Analysis of Variance Model for Effects on System Performance Measures: Trial Assignment Queue

\begin{tabular}{lll}
\hline & $F$ & $\mathrm{df}$ \\
\hline
\end{tabular}

(a) Main effects

Phase capacity

Phase entry rate

Case closure rate

$\begin{array}{cc}220.64^{*} & 1 \\ 0.33 & 1 \\ 233.12^{*} & 1 \\ 151.37^{*} & 3\end{array}$

Model

$$
R^{2}=95.7 \%
$$

(b) Interaction effects

Phase capacity

Phase entry rate

$\begin{array}{cc}365.10^{*} & 1 \\ 0.55 & 1 \\ 385.76^{*} & 1 \\ 14.09^{*} & 1 \\ 191.38^{*} & 4\end{array}$

Phase capacity $\times$ case closure rate

$$
R^{2}=97.6 \%
$$

${ }^{*} P<0.001$. 
and exit rate has a statistically significant impact on the two queues but not the other measures. These are the only statistically significant joint effects. ${ }^{20}$

The principal conclusions follow from queuing theory and support the model evaluation results. Varying the closure rate is essentially a direct change in the rate at which the final phase processes cases. Since this phase is critically related to the overall operation of the system and since almost $60 \%$ of the model's cases pass through this phase, a large impact is predictable. ${ }^{21}$ Altering phase capacity is simply a blunt expansion or contraction in the number of cases a system can handle. And queuing theory would lead us to expect that varying both the capacity and the service rate together should strongly affect system performance.

\section{MODEL UTILITY: POLICY IMPLICATIONS}

We end by showing how policy suggestions can result from the modeling results. Consider a director of court administration, assigned the task of improving pretrial felony case processing, trying to use these results. The analysis weighed, in effect, three policy alternatives favored by court officials or analysts: (a) increasing the number of judges (Neubauer et al., 1981a, pp. 330-412; Mahoney et al., 1985, pp. 27-28, 30); (b) adopting policies improving attorney availability and preparedness (Sipes et al., 1980, pp. 7-9, 12-14; Luskin and Luskin, 1987, p. 228); and (c) taking whatever steps possible to close out cases that have completed all pretrial hearings and motions, e.g., getting judges to use case-flow management techniques. These policy changes are akin to our varying, respectively, capacity, entrance rate, and exit rate in the simulations.

The analysis indicates that the administrator should implement the first and last policies. This is consistent with findings that programs emphasizing reduction in the number of cases in the final stages or increasing the number of cases the court can handle at the end of the process are helpful in reducing delay (Sipes et al., 1980, pp. 20-22; Neubauer et al., 1981a, pp. 415-417). An implication is that permanent programs to handle cases at the final stage of processing, to deal continuously, in effect, with reducing the queue the simulations show will constantly develop at this stage, would be effective in improving a court's performance.

\footnotetext{
${ }^{20} \mathrm{We}$ are sensitive to using significance tests for evaluating relationships when $n=24$. However, factorial analysis, as a technique developed for experimental research, is designed to isolate effects with a small number of cases.

${ }^{21}$ Cases can also exit the model through plea bargaining, either directly or through "possible disposition" (see Fig. 2), alternatives that can be randomly selected in any phase. Roughly $40 \%$ of the cases exited the system via this route, without ever entering the trial assignment phase.
} 
More generally, the simulations suggest that the court administrator should focus on getting cases through the final phase as quickly as possible. All available resources should be brought to bear on this phase. If the number of judges can be increased, they should handle only cases nearing trial assignment. (See Nagel et al., 1986, pp. 596-597.) Or if judges are only partially able or willing to use case-flow management techniques, they should be encouraged to employ them on cases in the system a long time. This is somewhat contrary to much research that argues that continuous case management must be applied. Constant management may indeed provide greater improvement than just concentrating on cases at the end. But the simulations indicate that focusing limited resources on these cases would have a larger impact on the judicial system than spreading equivalent resources over the whole process.

These results also argue that, among the actors in the system, policy should concentrate on judges. Judges play a critical role because of their ability to control the final-phase case closure rate and because they can prevent attorneys from controlling appearance scheduling.

A final lesson for our hypothetical administrator is the relative effectiveness of adopting policies singularly or jointly. The analysis suggests, for instance, that increasing the number of judges at the final phase (high increased capacity) will improve system performance, but the impact would not be as great as it could be if these judges are inexperienced in case management techniques or unwilling or unable to use them (low exit rate). Or forcing attorneys to meet appearance schedules and to be prepared (high entry rate) will, absent any other policy changes, cause the system to perform worse. The simulation model is particularly useful in demonstrating these relative effects of different policies.

\section{APPENDIX}

\section{Model Validation}

We assess the model's validity by comparing the pattern of its dynamic behavior to that of the actual system. Because of model assumptions that differ from the New York system, we do not expect the model to replicate static system measures in the individual case data. ${ }^{22}$ Also, actual data

${ }^{22}$ Model assumptions that differ from the New York City system are as follows.

(a) Phase capacity is fixed at 10 . In actuality, capacity may be greater than 10 , may not be uniform across all phases, and may have greater elasticity.

(b) All cases pass through all five phases, save those resolved by early plea bargaining or dismissal. In actuality, a judge has greater flexibility.

(c) Cases are always returned to queue, in any circumstances, if entry conditions are not met. In actuality, a judge may schedule the case for a time in the near-future and avoid sending it back into queue. 
collection stopped at a specified date, before some cases were concluded, whereas in the simulations, every case was concluded. All these differences work in the same direction, i.e., we expect the simulations to generate larger values on system measures than would the actual data.

What should be comparable is the dynamic pattern in the actual and simulated systems. To assess this, we focus, in Table AI, on the relationships among groups of cases in the simulated and actual systems, comparing relative values among defined groups of cases in the actual system to those values for the same groups in the model. Two system measures are used: processing time and number of appearances. The first three columns contain statistics for all cases in each data set, cases exiting without going through the trial assignment phase, and cases exiting via the trial assignment phase. The last column provides statistics on the behavior of trial assignment phase exiters before reaching that phase.

Standardized scores are used to compare the relationship of each subgroup's mean to the total sample mean. These values show that the relationship between the entire sample and the trial assignment group is similar in both the actual and the simulated data for the two system measures.

Table AI. Appearance and Processing Time Comparisons Between the Simulated and the Actual Data

\begin{tabular}{|c|c|c|c|c|}
\hline & $\begin{array}{c}\text { Entire } \\
\text { sample }\end{array}$ & $\begin{array}{c}\text { Exited } \\
\text { before } \\
\text { trial } \\
\text { phase }\end{array}$ & $\begin{array}{c}\text { Exited } \\
\text { via } \\
\text { trial } \\
\text { phase }\end{array}$ & $\begin{array}{c}\text { Trial-phase } \\
\text { cases } \\
\text { behavior } \\
\text { before } \\
\text { trial phase }\end{array}$ \\
\hline \multicolumn{5}{|c|}{ (a) Processing time } \\
\hline \multicolumn{5}{|l|}{ Simulated data } \\
\hline$Z$ score $^{a}$ & 1.000 & 0.072 & 1.441 & 0.237 \\
\hline Coefficient of variation & 0.899 & 1.323 & 0.614 & 0.597 \\
\hline \multicolumn{5}{|l|}{ Actual data } \\
\hline$Z$ score & 1.000 & -0.098 & 1.247 & 0.094 \\
\hline Coefficient of variation & 0.680 & 1.077 & 0.537 & 0.656 \\
\hline \multicolumn{5}{|c|}{ (b) Appearances } \\
\hline \multicolumn{5}{|l|}{ Simulated data } \\
\hline$Z$ score & 1.000 & 0.062 & 1.446 & 0.223 \\
\hline Coefficient of variation & 0.670 & 0.571 & 0.552 & 0.513 \\
\hline \multicolumn{5}{|l|}{ Actual data } \\
\hline$Z$ score & 1.000 & -0.033 & 1.230 & 0.148 \\
\hline Coefficient of variation & 0.584 & 0.885 & 0.489 & 0.494 \\
\hline
\end{tabular}

${ }^{a} Z$ scores are normed to one; thus, $Z=[($ subgroup mean - sample mean $) /$ sample $\mathrm{SD}]+1$. 
Table AII. Comparison of Extreme Cases Between Simulated and Actual Data

\begin{tabular}{lccc}
\hline & \multicolumn{3}{c}{ Percentage of } \\
\cline { 2 - 4 } Data source & Cases & System time & Appearances \\
\hline Simulation & 15.0 & 39.3 & 38.7 \\
Actual & 15.0 & 30.5 & 31.8 \\
Simulation & 25.0 & 56.8 & 55.5 \\
Actual & 25.0 & 46.2 & 47.1 \\
\hline
\end{tabular}

For example, the processing-time $z$ scores are 1.441 and 0.237 for the simulation and 1.247 and 0.094 for the actual data.

Comparing the coefficient of variation also indicates that relationships are similar in the simulated and in the actual data. Pretrial-phase plea bargained cases show the greatest variance, while the behavior of trial-phase cases before entering that phase shows the least. The greater variance for simulated cases probably reflects the model's assumption of uniform scheduling, in contrast to the flexible scheduling characteristic of the New York system.

By comparing characteristics of extreme cases, Table AII shows the similarity between the simulated processing time and appearance count distributions and those distributions in the actual data. In both data sets, the same percentage of cases at the high end of the distributions account for more than twice as many appearances and twice as much system time as the average case. Simulated cases at the high end account for a higher percentage of total appearances and processing time than do comparable cases in the actual data. These differences are congruent with the impact that would be caused by the difference between the model's assumptions and the workings of the actual system.

\section{Time Equations}

To capture variation in judicial scheduling behavior observed in the data for options $3 \mathrm{~d}$ and $3 \mathrm{e}$, distinct OLS regression equations were developed for scheduling to the next phase and for rescheduling within the same phase. As Table AIII shows, equations were defined for three groupings, i.e., the first four phases, the trial assignment phase for four or fewer appearances, and the trial assignment phase for more than four appearances. Variables were prosecution and defense time requests, an interaction to represent a joint request, a dummy for appearance productivity, the number of pretrial assignment appearances, the number of trial assignment appearances, and 
Table AIII. Scheduling and Rescheduling Equations: Regression Coefficients

\begin{tabular}{|c|c|c|c|c|c|}
\hline & \multicolumn{2}{|c|}{ Scheduling } & \multicolumn{3}{|c|}{ Rescheduling } \\
\hline & $\begin{array}{l}\text { Phases } \\
1 \text { to } 4\end{array}$ & $\begin{array}{c}\text { Trial } \\
\text { phase }\end{array}$ & $\begin{array}{l}\text { Phases } \\
1 \text { to } 4\end{array}$ & $\begin{array}{c}\text { Trial phase: } \\
\leq 4 \text { appearances }\end{array}$ & $\begin{array}{l}\text { Trial phase: } \\
>4 \text { appearances }\end{array}$ \\
\hline Intercept & 24.63 & 21.82 & 18.07 & 14.95 & 24.20 \\
\hline Prosecution request & 0.05 & 0.11 & -0.32 & -0.39 & -0.05 \\
\hline Defense request & 0.28 & 0.16 & 0.35 & 0.55 & 0.50 \\
\hline Both attorneys & -0.21 & -0.01 & $\mathbf{N A}^{a}$ & -0.02 & -0.02 \\
\hline $\begin{array}{l}\text { Appearance } \\
\text { productivity }\end{array}$ & -5.97 & NA & NA & NA & NA \\
\hline $\begin{array}{l}\text { Pretrial assignment } \\
\text { appearances } \\
\text { (at current time) }\end{array}$ & -0.23 & 0.83 & 0.66 & -0.63 & -1.84 \\
\hline $\begin{array}{l}\text { Trial assignment } \\
\text { appearances } \\
\text { (to date) }\end{array}$ & NA & -0.98 & NA & NA & -0.52 \\
\hline $\begin{array}{l}\text { Prosecution } \\
\text { response phase }\end{array}$ & 5.77 & NA & 5.16 & NA & NA \\
\hline $\begin{array}{l}\text { Judicial decision } \\
\text { phase }\end{array}$ & 1.53 & $\mathrm{NA}$ & 5.19 & NA & NA \\
\hline
\end{tabular}

${ }^{a}$ Variable not applicable for that equation.

two dummy control variables for whether the case was in the prosecution response or in the judicial decision phase. These variables were consistently statistically significant throughout analyses of judges' scheduling decisions. There were no significant differences in the scheduling equations estimated for both parts of the final phase, so a single equation was used. Table AIII contains the regression coefficients $(b)$ for each variable (equations are read down).

Each time a scheduling function was performed, the model first determined values for two variables: appearance productivity (yes/no) and which attorney requested time (prosecuting, defense, both, or neither). Cases were randomly assigned to these categories (independently for each variable) based on probabilities for the comparable phase/scheduling subgroups in the appearance case data.

If the attorney request category was other than neither, the model used a random number generator to select a time from the appearance case distribution of times for each category. The random number generator used the mean of these distributions and assumed an exponential distribution for each variable to select the time values used in the equations.

The scheduling and rescheduling functions are probabilistic but do use parameter estimates from the New York City data. A model developed for 
a different locale should develop estimates for these functions using data from an appropriate sample.

\section{ACKNOWLEDGMENTS}

We want to thank The Florence V. Burden Foundation for their financial support, Nicip Doganaksoy, Charles Meara, and Stella Meierfield for their insights and assistance, and the referees for their critiques. The order in which the authors are listed was randomly determined.

\section{REFERENCES}

Blumstein, A. (1981). Court delay and queueing theory. In Martin, J. A., and Prescott, E. A. (eds.), Appellate Court Delay, National Center for State Courts, Williamsburg, Va, pp. 155-159.

Chaiken, J., Crabill, T., Holliday, L., Jaquette, D., Lawless, M., and Quade, E. (1976). Criminal Justice Models: An Overview, National Institute of Law Enforcement and Criminal Justice, Washington, D.C.

Church, T. W. (1982) Examining Local Legal Culture, United States Department of Justice, Washington, D.C.

Church, T. W., Carlson, A., Lee, J., and Tan, T. (1978). Justice Delayed: The Pace of Litigation in Urban Trial Courts, National Center for State Courts, Williamsburg, Va.

Eisenstein, J., and Jacob, H. (1977). Felony Justice: An Organizational Analysis of Criminal Contr, Little, Brown, Boston.

Flemming, R. B., Nardulli, P. F., and Eisenstein, J. (1987). The Timing of Justice in Felony Trial Courts, Unpublished manuscript, University of Illinois, Urbana.

Hann, R. G. (1973). Decision Making in the Canadian Criminal Court System: A Systems Analysis, Centre of Criminology, University of Toronto, Toronto.

Jacobs, N., and Chayet, E., with Meara, C. (1986). Bang the Gavel Slowly, John Jay College, CUNY, New York.

Jennings, J. B. (1971a). Quantitative Models of Criminal Courts. New York City Rand Institute, New York.

Jennings, J. B. (1971b). The Flow of Arrested Adult Defendants Through the Manhattan Criminal Courts in 1968 and 1969, New York City Rand Institute, New York.

Luskin, M. L., and Luskin, R. C. (1986). Why so fast, why so slow? Explaining case processing time. J. Crim. Law Criminol. 77: 190-214.

Luskin, M. L., and Luskin, R. C. (1987). Case processing times in three courts. Law Policy 9 : 207-232.

Mahoney, B., Sipes, L. L., and Ito, J. A. (1985). Implementing Delay Reduction and Delay Prevention Programs in Urban Trial Courts, National Center for State Courts, Williamsburg, $\mathrm{Va}$.

Nagel, S., Beeman, M., and Reed, J. (1986). Optimum sequencing of court cases to reduce delay. Univ. Ala. Law Rev. 37: 583-638.

Navarro, J. A., and Taylor, J. G. (1967). Data analyses and simulation of court system in the District of Columbia for the processing of felony defendants. In President's Report on Law Enforcement and Administration of Justice, Science and Technology, U.S. Government Printing Office, Washington, D.C., pp. 199-215. 
Neubauer, D. W. (1974). Criminal Justice in Middle America, General Learning Press, Morristown, N.J.

Neubauer, D. W., Lipetz, M., Luskin, M. L., and Ryan, J. P. (1981a). Managing the Pace of Justice, National Institute of Justice, Washington, D.C.

Neubauer, D. W., Lipetz, M., Luskin, M. L., and Ryan, J. P. (1981b). Managing the Pace of Justice: Executive Summary, National Institute of Justice, Washington, D.C.

Nimmer, R. T. (1976). The Nature of System Change, American Bar Foundation, Chicago.

Reed, J. H. (1973). The Application of Operations Research to Court Delay, Praeger, New York. Resnick, J. (1982). Managerial judges. Harvard Law Rev. 96: 374-448.

Sipes, L. L., Carlson, A., Tan, T., Aikon, A. A., and Page, R. W. (1980). Managing to Reduce Delay, National Center for State Courts, Williamsburg, Va.

Watson, H. J. (1981). Computer Simulation in Business, John Wiley \& Sons, New York. 